\title{
Polifenoli - med zaščito nevronov in potencialno toksičnostjo
}

\author{
Lea POGAČNIK ${ }^{1,2}$, Rui Fernando Marques da SILVA ${ }^{3}$
}

Received January 31, 2020; accepted April 27, 2020.

Delo je prispelo 31. januarja 2020, sprejeto 27. aprila 2020

Polifenoli - med zaščito nevronov in potencialno toksičnostjo Izvleček: Polifenoli predstavljajo skupino sekundarnih metabolitov, ki jih najdemo v živilih, kot so: sadje, zelenjava, vino, čaj, oljčno olje in čokolada. Te spojine imajo poleg močnih antioksidantivnih lastnosti tudi protivnetne. Številne študije so potrdile njihovo potencialno vlogo pri preprečevanju in zdravljenju različnih patoloških stanj, povezanih z oksidativnim stresom in vnetjem. Mednje sodijo rak, srčno-žilne in nevrodegenerativne bolezni. Slednje globalno predstavljajo enega od glavnih vzrokov smrtnosti in so zato veliko socialno in finančno breme. Številne raziskave so pojasnile nekatere mehanizme delovanja polifenolov kot antioksidativnih in protivnetnih spojin in pojasnile njihovo vlogo pri zdravljenju/preprečevanju določenih bolezenskih stanj. Ugotavljajo, da polifenole lahko uporabljamo kot zaščitne/profilaktične spojine kot tudi terapevtske spojine. Zadostno količino lahko dosežemo z uživanjem prehrane, bogate $\mathrm{s}$ polifenoli, v obliki prehranskih dopolnil ali s formulacijami, kot so nutracevtiki. Zdravstveni učinki polifenolov so odvisni tako od zaužite količine kot od njihove biološke razpoložljivosti. Vendar pa lahko njihova čezmerna uporaba povzroči pomisleke glede varnosti zaradi kopičenja teh molekul v organizmu, zlasti če upoštevamo, da so predpisi na področju prehranskih dopolnil zelo ohlapni. Zato se pričujoči pregledni članek osredotoča na poglavitne pozitivne učinke polifenolov, ki izvirajo iz naravnih virov, $\mathrm{z}$ vidika zaščite nevronov, obravnava pa tudi možne varnostne pomisleke $z$ vidika nevrotoksičnosti.

Ključne besede: polifenoli; zaščita nevronov; nevrotoksičnost; biološka razpoložljivost; modeli in vitro
Poyphenols - between neuroprotection and neurotoxicity Abstract: Polyphenols are a group of secondary metabolites found in a wide variety of foods, such as fruits, vegetables, wine, tea, olive oil and chocolate. These compounds, in addition to their antioxidant activity, also possess strong anti-inflammatory properties. Numerous studies have therefore confirmed their potential role in preventing and treating various pathological conditions associated with oxidative stress and inflammation. Among these, the most prevalent ones include cancer, cardiovascular and neurodegenerative diseases, which globally represent one of the main causes of death and are therefore a major social and financial burden, Numerous studies have clarified some of the mechanisms of action of polyphenols as antioxidant and anti-inflammatory compounds and have clarified their role in treatment/prevention of certain conditions. It was shown that polyphenols could be used both as protective/prophylactic compounds and as therapeutic compounds. A sufficient amount can be achieved either by consuming a diet, rich in polyphenols, or in the form of dietary supplements and nevertheless with formulations such as nutraceuticals. The health effects of polyphenols depend not only on the amount consumed but also on their bioavailability. However, their overconsumption can cause safety concerns due to the accumulation of these molecules in the body, especially considering that the regulatory legislation in the field of dietary supplements is rather loose. Therefore, this review focuses on the major positive effects of natural-derived polyphenols, and addresses potential safety concerns, with a focus on neuroprotection and neurotoxicity.

Kew word: polyphenols; neuroprotection; nevrotoxicity; bioavailability; models in vitro

1 Univerza v Ljubljani, Biotehniška fakulteta, Oddelek za živilstvo, Ljubljana, Slovenija

2 Korespondenčni avtor, e-naslov: lea.pogacnik@bf.uni-lj.si

3 Univerza v Lizboni, Fakulteta za farmacijo, Research Institute for Medicines (iMed.ULisboa), Lizbona, Portugalska 


\section{UVOD}

Polifenoli (polifenolne spojine, fenolne spojine) so naravno prisotna mikrohranila, ki jih rastline nujno potrebujejo za svoj obstoj (Bravo, 1998). Mednje sodijo spojine, zgrajene iz enega ali več fenolnih obročev (Slika 1), najdemo pa jih v številnih živilih, kot so vino, zeleni čaj, grozdje, zelenjava, rdeče sadje in kava (D’Archivio et al., 2007; Manach et al., 2004). Večina polifenolov sodi med močne antioksidante (Noda et al., 2002; Zafra-Stone et al., 2007), imajo pa lahko tudi protivnetne učinke (Fernandes et al., 2006; Yu et al., 2016). Ravno to je pritegnilo pozornost številnih raziskovalcev, ki so dokazali njihovo potencialno vlogo pri preprečevanju in zdravljenju različnih patoloških stanj, povezanih $\mathrm{z}$ oksidativnim stresom in vnetnimi procesi. Mednje sodijo močno razširjene bolezni, kot so: rak, srčno-žilne in nenazadnje tudi nevrodegenerativne bolezni, med katere sodita tudi Alzheimerjeva in Parkinsonova bolezen (Abib et al., 2011; Afshari et al., 2019; Hartman et al., 2006; Liu et al., 2016; Poti et al., 2019). Za slednji kronični stanji je značilna predvsem izguba nevronov in nevrodegeneracija. Čeprav so klinične manifestacije nevrodegenerativnih bolezni povezane predvsem s staranjem, velja, da se začetek bolezni in izguba nevronov začneta pojavljati postopoma skozi celotno življenje, precej preden se pojavijo prvi simptomi. Ena glavnih težav pri izbiri terapij pri nevrodegenerativnih boleznih je, da z zdravljenjem pogosto začnemo šele, ko opazimo prve simptome in ko je veliko število nevronov že odmrlo. Ravno zato je zelo pomembno, da poznamo načine, kako ohraniti nevrone zdrave in kako zmanjšati tveganje za nevrodegeneracijo. Novi pristopi za preprečevanje in/ali premagovanje nevrodegeneracije bi dolgoročno lahko povečali zdravje možganov in drugih delov živčevja ter zmanjšali tveganje za nevrodegeneracijo, zato bi s tem imeli velik vpliv ne samo na družbo kot tako, temveč tudi na svetovno ekonomijo.

Nekatere raziskave so $\mathrm{v}$ preteklosti pokazale, da ima prehrana lahko ključno vlogo pri ohranjanju zdravja, kar je sprožilo razvoj cele vrste prehranskih dopolnil (Virmani et al., 2013). Kot ena izmed možnih rešitev se tako kaže naravno povečanje notranje obrambe možganov in preprečevanje ali vsaj zmanjšanje začetnih poškodb nevronov, ki vodijo v nevrodegenerativne procese. Ravno zato se je več raziskav osredotočilo na pomen uživanja naravnih proizvodov ali ustreznih prehranskih dopolnil, ki bi lahko zaščitila nevrone pred poškodbami. Običajna človeška prehrana je sicer bogata s polifenoli. Po podatkih Phenol-Explorer (Perez-Jimenez et al., 2010) jih povprečen Evropejec zaužije okrog $1 \mathrm{~g}$ na dan. Še posebej dobre vire polifenolov predstavljajo oreščki, čaj, kava, češnje, citrusi, zelenjava, čokolada in rdeče vino, ki so del tako imenovane mediteranske prehrane, ki jo UNESCO<smiles>O=C1c2c(O)cc(O)cc2OC(c2ccc(O)c(O)c2)C1O</smiles>

kvercetin<smiles>O=C(O[C@H]1Cc2c(O)cc(O)cc2O[C@H]1c1cc(O)c(O)c(O)c1)c1cc(O)c(O)c(O)c1</smiles>

resveratrol<smiles>Oc1ccc(/C=C/c2cc(O)cc(O)c2)cc1</smiles>

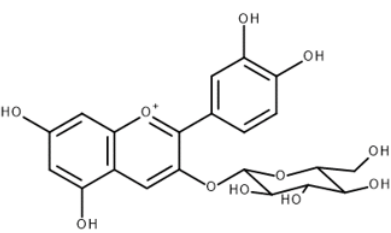

cianidin-3-glukozid (C3G)<smiles>Cc1cc(/C=C/C(=O)CC(=O)/C=C/c2ccc(O)c(O)c2)ccc1O</smiles>

kurkumin

Slika 1: Predstavniki nekaterih polifenolov, vključenih v raziskave zaščite nevronov

Figure 1: Representatives of polyphenols compounds that showed neuroprotection properties 
uvršča na seznam nesnovne kulturne dediščine. V različnih državah pa se glavni prehranski viri polifenolov lahko razlikujejo glede na tradicionalne prehranjevalne navade. Tako so v severno in vzhodnoevropskih državah glavni prehranski viri polifenolov predvsem napitki, kot sta kava in čaj (Grosso et al., 2014; Zamora-Ros et al., 2016), medtem ko so v južnoevropskih in sredozemskih državah pomembni prehranski viri oreški, oljčno olje, sadje in zelenjava (Godos et al., 2017; Tresserra-Rimbau et al., 2013). Živilska industrija se je v zadnjem času začela zanimati tudi za stranske produkte, ki nastanejo pri predelavi sadja in zelenjave (npr. oljčne pogače, čebulni listi ipd.), saj so lahko bogat vir polifenolov in jih zato lahko uporabimo kot dodatke $\mathrm{v}$ funkcionalnih živilih ali kot prehranska dopolnila (Marranzano et al., 2018). Zanimivo je, da so nekateri polifenoli značilni samo za določeno sadje ali zelenjavo, medtem ko večino lahko najdemo v več virih (D’Archivio et al., 2010). Večina sadja in zelenjave vsebuje več kot eno značilno vrsto polifenolov (Lorenzo et al., 2019). Zavedati pa se moramo, da je količina polifenolov $\mathrm{v}$ isti rastlini lahko tudi različna in je odvisna od posameznega dela rastline korenine, stebla, listi, cvet, plod), pa tudi od klimatskih in rastnih razmer (Lorenzo et al., 2019; Marranzano et al., 2018). Ravno zato je zelo težko oceniti dejansko količino naravno zaužitih polifenolov. Vse to je potrebno upoštevati, ko govorimo o pozitivnih učinkih polifenolov na naše zdravje v primerjavi z možnimi negativnimi posledicami, povezanimi s potencialnimi toksičnimi učinki kot posledice njihovega kopičenja v telesu.

\section{POZITIVNI UČINKI POLIFENOLOV NA MOŽGANE}

Nevrodegenerativne bolezni so patološka stanja, pri katerih se določene skupine nevronov poškodujejo ali odmrejo, kar vpliva na normalno delovanje centralnega živčnega sistema in se izraža s slabšimi kognitivnimi in/ ali motoričnimi funkcijami. Mnoge od teh bolezni so običajno povezane s staranjem, pri čemer velja, da se nevrodegeneracija skozi leta pojavlja v subklinični obliki, pri čemer prihaja do odmiranja nevronov postopoma skozi celo življenje, še preden so opazni prvi klinični znaki. Trenutne napovedi kažejo, da se bo število dementnih prebivalcev stalno povečevalo in lahko do leta 2030 prizadene kar polovico starostnikov (Noble \& Burns, 2010). Številne raziskave (Glass et al., 2010; Lee et al., 2003; Ono et al., 2003; Weinreb et al., 2004) so proučevale celične mehanizme nevrodegeneracije pri več patoloških stanjih, kot so Alzheimerjeva, Parkinsonova in Huntingtonova bolezen, pa tudi amiotrofična lateralna skleroza. Vendar zaenkrat še ni na voljo učinkovitih terapij za zdravljenje teh bolezni, z določenimi zdravili lahko le zmanjšamo ali začasno zavremo njihove simptome.

Kljub specifičnim kliničnim slikam pa ima veliko teh bolezni nekatere skupne mehanizme, med katerimi prevladujeta nevronsko vnetje (Amor et al., 2010) in oksidativni stres (Glass et al., 2010; Tarawneh \& Galvin, 2010). V preglednem članku (Calabrese et al., 2007) je bil zato natančno predstavljen pomen zmanjšanja ekspresije oksidativno-stresnih regulatornih genov pri staranju in nevrodegeneraciji, pa tudi možna zaščita $\mathrm{z}$ antioksidanti. Ravno zato so pristopi, ki lahko upočasnijo ali preprečijo nastanek bolezni in preprečujejo nevrodegeneracijo, enako pomembni kot tisti, ki so namenjeni zdravljenju teh bolezni. Pri tem je bila prehrana prepoznana kot pomembna, kar je vodilo v celo vrsto raziskav, osredotočenih na pomen uživanja izdelkov, tako v obliki živil kot v obliki prehranskih dopolnil, ki lahko zaščitijo nevrone (Costa et al., 2016; Solanki et al., 2015).

Biološka aktivnost molekul, ki izvirajo iz živil, je bila prvič prepoznana v poznih 40. letih prejšnjega stoletja, ko sta Schraufstatter in Bernt (Schraufstatter \& Bernt, 1949) dokazala antibakterijsko delovanje kurkumina. Kasneje so pritegnili pozornost tudi drugi prehranski polifenoli, zlasti resveratrol, ki je bil prepoznan kot možni razlog za povezavo med uživanjem rdečega vina v Franciji in nizko stopnjo srčno-žilnih bolezni (Sun et al., 2002). Zasluge za pozitivne učinke lahko pripišemo antioksidativnim lastnostim prehranskih polifenolov, $\mathrm{v}$ tem primeru resveratrola.

$\mathrm{V}$ literaturi pa je je opisanih tudi več primerov polifenolov, ki kažejo obetavne sposobnosti preprečevanja in zdravljenja nevrodegenerativnih bolezni (Gray et al., 2018; Lorenzo et al., 2019; Mani et al., 2018; Palazzi et al., 2018; Ullah \& Khan, 2018; Ulusoy \& Sanlier, 2019). Veliko raziskav je bilo ravno tako narejenih na resveratrolu, za katerega je bilo ugotovljeno, da lahko zaščiti nevrone v študijah in vitro (Granzotto \& Zatta, 2014; Sun et al., 2002; Zhang et al., 2013). Zanj je bilo tudi dokazano, da sodeluje pri zmanjšanju nevronskega vnetja, ki ga povzroča mikroglija, pri varovanju možganov pred hipoksično-ishemičnimi poškodbami in pri izboljšanju kognitivnih sposobnosti v modelu Alzheimerjeve bolezni (Granzotto \& Zatta, 2014; Sun et al., 2002; West et al., 2007; Zhang et al., 2013). Zdi se, da zmanjšuje tudi s staranjem povezano zmanjšanje kognitivnih zmožnosti in poveča kognitivno funkcijo z modulacijo SIRT1 (Cao et al., 2018). Opisani pa so tudi še drugi možni mehanizmi zaščite nevronov (Menard et al., 2013; Pan et al., 2019).

Obstaja še več drugih študij, ki so vključevale polifenole, zlasti tiste iz rdečega vina ali zelenega čaja (Mandel et al., 2006), in so se osredotočile na njihovo vlogo pri zaščiti nevronov pri različnih nevrodegenerativnih boleznih. Med njimi je tudi študija, ki je dokazala zaščito 
nevronov $\mathrm{z}$ epigalokatehin galatom (EGCG) pred nevrotoksičnimi učinki $\beta$-amiloidnih proteinov (Zhang et al., 2014). Ista molekula je kazala tudi sposobnost, da s povečanjem LC3-II (Lee et al., 2015) zavira translokacijo Baxa in citokroma c, lahko pa tudi modulira mitohondrijsko funkcijo (Oliveira et al., 2016). Dokazano je bilo tudi, da lahko EGCG z lahkoto prestopa model človeške krvno-možganske membrane (BBB) in zaščiti nevrone pred celično smrtjo kot posledico oksidativnega stresa in vitro (Pogačnik et al., 2016). Podobna študija na živalskem modelu BBB je prav tako pokazala, da bi lahko nekateri ostali flavonoidi lahko dosegli možgane (Faria et al., 2014), ni pa še povsem jasno, kakšni so mehanizmi zaščite nevronov.

Potrebno pa je poudariti, da se pozitivna vloga polifenolov po svoji intenzivnosti razlikuje tudi glede na izvor in vrsto živila. Na primer, pri modelu podgan $\mathrm{z}$ inducirano Alzheimerjevo boleznijo je bilo ugotovljeno, da je bila boljša zaščita nevronov dosežena $z$ dodatkom zelenega čaja kot s črnim čajem ali rdečim vinom (Schimidt et al., 2017). V podobnem mišjem modelu je sok granatnega jabolka ?vplival na zmanjšanje odlaganja amiloidov in istočasno izboljšal rezultate testov vedenja (sposobnost učenja in pomnjenja v Morrisovem vodnem labirintu in hitrost plavanja) živali (Hartman et al., 2006). Zanimiva je nedavna objava, $\mathrm{v}$ kateri je zapisano, da je $\mathrm{z}$ dodatkom borovnic $\mathrm{v}$ hrano podgan mogoče zmanjšati vnetno reakcijo (Willis et al., 2010), še zlasti pri starejših osebkih. Opazili pa so tudi zaščito nevronskih celic pred oksidativnim stresom in zmanjšano aktivacijo mikroglije (Garcia et al., 2017). Na modelu Parkinsonove bolezni pa so bili doseženi podobno dobri rezultati s kurkuminom (Mythri \& Bharath, 2012), pa tudi z nekaterimi zdravilnimi rastlinami, ki se uporabljajo v tradicionalni medicini, kot je npr. vrsta Centella asiatica (L.) Urban, s katero so dosegli tako zmanjšanje mitohondrijske disfunkcije kot tudi oksidativnega stresa. Z uporabo ekstraktov iste rastline je prišlo tudi do izboljšanja kognitivne zmožnosti pri Alzheimerjevi bolezni in vivo (Gray et al., 2018).

Poleg opisanih primerov naraščajoče število raziskav kaže na možnost epigenetske modulacije preko uživanja polifenolov, in sicer le-ti lahko vplivajo na modulacijo pro- in protivnetnih mikroRNK (Lee et al., 2015; Tili \& Michaille, 2016). Nedavni pregledni članek (Boyanapalli \& Tony Kong, 2015) je izpostavil epigenetsko modulacijo kurkumina, vključno z inhibicijo DNK metiltransferaz, regulacijo sprememb histona $\mathrm{z}$ regulacijo histon acetiltransferaze in histonske deacetilaze (HDAC), pa tudi $z$ regulacijo mikroRNA.

$\mathrm{Na}$ podlagi opisanih izsledkov raziskav lahko zaključimo, da je vključitev polifenolov v prehrano ali njihova uporaba v obliki prehranskih dopolnil ali nutracevtikov obetavna pri preprečevanju več različnih patologij, med katere sodijo tudi nevrodegenerativne bolezni. Obsežen seznam vseh raziskanih bolezenskih stanj (depresija, ekscitotoksičnost glutamata, epilepsija, motnja sluha in vida ter nevrodegenerativne bolezni), pa tudi študije in vitro, ex vivo in in vivo, pri katerih so bili ovrednoteni mehanizmi delovanja polifenolov, je podan v preglednem članku Szwajgier et al. (2017). Do podobnih zaključkov so prišle tudi zanimive epidemiološke študije na splošni populaciji, na kateri so ugotavljali povezavo med prehranskimi polifenoli in depresivnimi simptomi (Chang et al., 2016; Godos et al., 2018).

Opisane potencialne koristne lastnosti polifenolov, bodisi kot zaščitnih/profilaktičnih spojin bodisi kot terapevtskih molekul, lahko dosežemo tako $\mathrm{z}$ uživanjem naravne prehrane, bogate s polifenoli, kot tudi $\mathrm{z}$ uporabo prehranskih dopolnil ali v obliki nutracevtikov. Dokazano je bilo tudi, da so učinki polifenolov na zdravje odvisni tudi od zaužite količine in njihove biološke razpoložljivosti (Tresserra-Rimbau et al., 2018). Po drugi strani pa prekomerno uživanje polifenolov lahko povzroči pomisleke glede varnosti zaradi kopičenja velikih količin teh molekul v organizmu, zlasti če upoštevamo ohlapno zakonodajo na področju prehranskih dopolnil.

\section{MODELI ZA UGOTAVLJANJE VLOGE POLIFENOLOV V TELESU}

\subsection{PREBAVNI MODEL}

Biološka razpoložljivost polifenolov je ključna za njihove pozitivne/negativne učinke na človeško telo. Nekatere raziskave kažejo, da je le-ta majhna (Pandareesh, Mythri, \& Srinivas Bharath, 2015), opisani pa so bili že tudi potencialno toksični učinki, kadar so bile učinkovine uporabljene v velikih koncentracijah. Prebavni modeli in vitro so zato zelo pomembni del raziskav za preučevanje strukturnih sprememb, prebavljivosti in sproščanja sestavin hrane v simuliranih pogojih prebave. Najpogosteje uporabljene biološke molekule, vključene v prebavne modele, so prebavni encimi (pankreatin, pepsin, tripsin, kimotripsin, peptidaza, $\alpha$-amilaza in lipaza), žolčne soli in mucin, temperatura prebave pa je $37^{\circ} \mathrm{C}$. Najpogosteje uporabljeni modeli simulirajo prebavo $\mathrm{v}$ želodcu in $\mathrm{v}$ tankem črevesu. Želodčna faza se začne $\mathrm{z}$ dodatkom raztopine pepsina in uravnavanjem $\mathrm{pH}$ na 2,0 po inkubaciji pri $37^{\circ} \mathrm{C}$ v pokriti stresni vodni kopeli 1 uro. Faza tankega črevesja se začne s uravnavanjem $\mathrm{pH}$ na 5,3, sledi dodajanje encimske raztopine tankega črevesa (lipaze, pankreatina in žolčnih soli). Končni pH vzorca je uravnan na 7,5, čemur sledi 2-urna inkubacija pri $37^{\circ} \mathrm{C}$. Vzorce med prebavo lahko večkrat analiziramo s sistemom HPLC/DAD, da ugotovimo pretvorbe bioak- 
tivnih spojin (polifenolov) (Hur et al., 2011; Minekus et al., 2014).

\subsection{MODEL KRVNO-MOŽGANSKE PREGRADE (BBB)}

Glede na to, da je bila na celičnih modelih dokazana zmožnost polifenolov, da zaščitijo nevrone, je ključno vedeti, ali izbrane spojine dosežejo ciljni organ (možgane), saj so lahko samo na ta način učinkovite. Večina modelov in vitro uporablja poenostavljen in vitro model, ki posnema lastnosti človeške BBB, in je sestavljen iz monoplastnih mikrovaskularnih endotelijskih celic človeških možganov (HBMEC) (Bernas et al., 2010). Te celice je mogoče gojiti na porozni membrani, pri čemer dobimo model z dvema predeloma, zgornji predstavlja krvni obtok, spodnji pa možgansko tkivo. Prisotnost molekul $\mathrm{v}$ spodnjem predelu kaže na to, da so le-te zmožne preiti BBB in so tako razpoložljive za možgane (Deli et al., 2005; Faria et al., 2012; Faria et al., 2010). Pri tem pa je seveda treba biti pozoren na to, da ne pride do poškodovanja HBMEC, kar se zagotovi z meritvami električne prevodnosti in prehajanja fluorescentno označenega barvila.

\subsection{CELIČNE KULTURE}

Zmožnost polifenolov, da zaščitijo nevrone (ali njihovo nevrotoksičnost), lahko ugotavljamo $\mathrm{z}$ različnimi modeli in vitro. Kot preprost model lahko uporabimo primarne nevronske celične kulture iz možganov podgan, ki veljajo za najbolj dovzetne za nevrodegenerativne spremembe (Lee et al., 2003; Pogačnik et al., 2016; Zhang et al., 2013). Večinoma se pri teh raziskavah uporablja astrocite in mikroglije, ki so glavni protagonisti možganskega imunskega odziva (Capiralla et al., 2012; Garcia et al., 2017; Nones et al., 2010; Willis et al., 2010; Yamamoto et al., 2017). Celični stres za posnemanje patoloških stanj $\mathrm{v}$ kontrolnih celicah in celicah, ki jih tretiramo s polifenoli, je potrebno izbrati glede na bolezen, ki jo želimo inducirati. $V$ ta namen se uporabljajo: izpostavljenost oksidativnemu okolju (Aquilano et al., 2008), MPP + (široko uporabljani Parkinsonov induktor) (Anandhan et al., 2013; Mani et al., 2018), A $\beta$-peptidi za AD (Zhang et al., 2013) ali bakterijski lipopolisaharid (LPS) kot induktor nevronskega vnetja (Capiralla et al., 2012). Z uporabo teh modelov lahko ocenimo celično smrt in njene specifične mehanizme (apoptoza, nekroza, nekroptoza, avtofagija) ter parametre in poti oksidativnih poškodb, vnetnega odziva in epigenetskih sprememb.

Najobetavnejše rezultate, pridobljene na modelih in vitro, je potrebno preveriti tudi z modeli in vivo, na primer na toksikološko tretiranih glodavcih (Pan et al., 2019; Rasheed et al., 2018) ali glodavcih s specifičnimi boleznimi (Gray et al., 2018; Schimidt et al., 2017), ki jih lahko hranimo $\mathrm{z}$ običajno hrano, s polifenolno bogatimi rastlinskimi ekstrakti ali pa izolirano bioaktivno molekulo polifenola. Te raziskave so pomembne tudi za oceno stranskih učinkov in vivo in za ugotavljanje varne uporabe kateregakoli preiskovanega polifenola (Charradi et al., 2018; Hu et al., 2018; Liu et al., 2017; Shen et al., 2017). Rezultate študij in vitro in rezultate na živalskih modelih pa je potrebno potrditi tudi s človeško pilotno študijo, v kateri je mogoče spremljati koristne in škodljive učinke (Molino et al., 2016).

\section{VARNOST V SVETU POLIFENOLOV}

Zaenkrat se je le malo raziskav osredotočilo na varno uporabo polifenolov za preprečevanje in zdravljenje bolezni, čeprav je to ključnega pomena za nadaljnje spodbujanje njihove uporabe za zagotavljanje zdravja ljudi. V naši študiji (Pogačnik et al., 2016) smo ocenili tri strukturno različne flavonoidne polifenole: kvercetin, (eden izmed najbolj zastopanih flavonoidov $\mathrm{v}$ živilih), monomerni flavanol epigalokatehin galat EGCG (najdemo ga $\mathrm{v}$ nekaterih semenih stročnic, $\mathrm{v}$ grozdju in $\mathrm{v}$ zelenem čaju (Afzal et al., 2015; Rezai-Zadeh et al., 2008)) in antocianin cianidin-O-3-glukozid (C3G), ki ga najdemo kot pigment $\mathrm{v}$ številnih rdečih jagodah, zlasti v borovnicah (Crozier et al., 2009; Kelly et al., 2017). Ti polifenoli so pokazali zmerno do veliko antioksidativno učinkovitost $\mathrm{z}$ antioksidativnimi testi in vitro, več avtorjev pa je ugotovilo, da jih je mogoče po peroralni uporabi določiti v plazmi v relativno velikih koncentracijah (Egert et al., 2008; Kay et al., 2005; Mereles \& Hunstein, 2011). Vsi trije polifenoli so v naši študiji (Pogačnik et al., 2016) pokazali raznolik profil glede na preučevane parametre. Medtem ko je EGCG pokazal zmerno nevrotoksičnost, je bila to molekula, ki je najmanj poškodovala model BBB in je najbolj učinkovito zaščitila primarne podganje nevrone pred nekrozo in apoptozo, povzročeno $\mathrm{z}$ oksidativnim stresom. Po drugi strani je C3G sicer kazal zelo majhno nevrotoksičnost, a je primarne podganje nevrone zaščitil le pred nekrozo, ne pa tudi pred apoptozo; poleg tega je že pokazal rahlo destabilizacijo modela BBB. In končno, kljub številnim obetavnim raziskavam (Carrasco-Pozo et al., 2019; Dajas et al., 2015; Zhu et al., 2013), je kvercetin pokazal najslabši profil, saj je močno poškodoval model $\mathrm{BBB}$, bil je zmerno do zelo nevrotoksičen, medtem ko nevronov praktično ni zaščitil pred oksidativnim stresom (Slika 2).

Kot že omenjeno, je le malo raziskav osredotočenih 


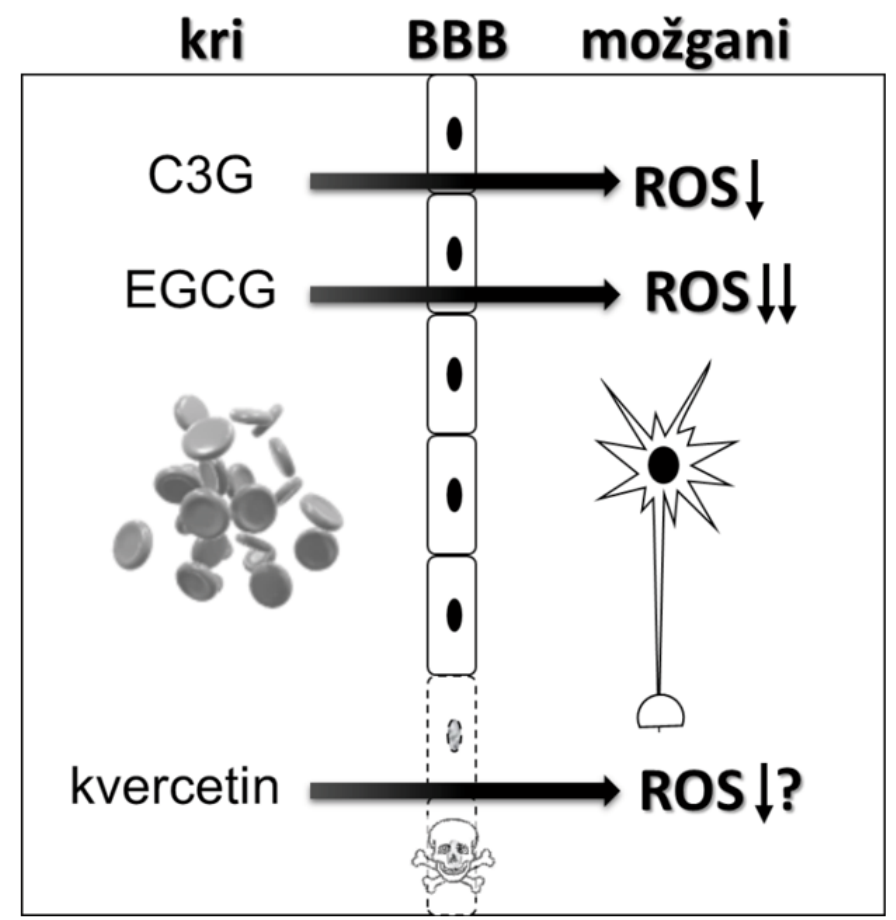

Slika 2: Shema prehajanja izbranih polifenolov (cianidin-3-glukozid (C3G), epigalokatehin galat (EGCG) in kvercetin) preko modela krvno-možganske pregrade (BBB) in njihov vpliv na zaščito primarnih podganjih nevronov pred reaktivnimi kisikovimi spojinami (ROS).

Figure 2: Schematic presentation of blood-brain barrier (BBB) model, crossed by selected polyphenols compounds (cyanidine$\mathrm{O}$-3-glucoside $(\mathrm{C} 3 \mathrm{G})$, epigallocatechin gallate (EGCG) and quercetin) and their neuroprotection against reactive oxygen species (ROS).

na toksičnost oziroma varnost uživanja polifenolov. Nekatere študije navajajo, da je redno uživanje zelenega čaja in ekstraktov zelenega čaja varno (Shen et al., 2017) zlasti v obliki tradicionalne infuzije (Liu et al., 2017; Wang et al., 2012), vendar svarijo pred uporabo koncentriranih ekstraktov $\mathrm{z}$ velikim odmerki posameznih sestavin $\mathrm{v}$ trdni obliki. Zato bodo potrebne dodatne študije, da se zagotovi njihova varna uporaba (Hu et al., 2018). Rezultati raziskav kažejo, da je neposredna uporaba zmernih odmerkov resveratrola varna in lahko zaščitijo srce (Johnson et al., 2011). Uporaba dodatka resveratrola (Longevinex) v študiji na živalih ni povzročila škodljivih učinkov, kar kaže na koristne učinke in varno uporabo (Sangeetha et al., 2013). Uživanje ekstrakta grozdnih pečk je bilo varno za zdrave podgane tudi v relativno velikih ponavljajočih se odmerkih. Pokazali so se tudi antioksidativni in protivnetni učinki (Charradi et al., 2018). Nasprotno pa so rezultati raziskave, kjer so diabetičnim mišim intraperitonealno vbrizgavali velike odmerke EGCG, pokazali na kardiotoksičnost (Rasheed et al., 2018).

Učinkovitost polifenolov je mogoče izboljšati z njihovo vključitvijo v nove farmacevtske formulacije, s katerimi bi jih tarčno dostavljali. S tem bi se izognili po- tencialnim škodljivim učinkom, kot je pokazala nedavna študija $\mathrm{z}$ uporabo kurkumina $\mathrm{v}$ obliki nanomicelijske trdne disperzije (Parikh et al., 2018). Vendar pa se moramo zavedati, da imamo na trgu slabo regulirana komercialna prehranska dopolnila in nutracevtike, kar je lahko problematično $\mathrm{z}$ vidika njihove varne uporabe, kar je poudarjeno tudi v preglednem članku, v katerem so avtorji sistematično pregledali medicinske preparate na osnovi granatnega jabolka in njihovo uporabo pri zdravljenju rakavih obolenj (Vlachojannis et al., 2015).

\section{ZAKLJUČEK}

Polifenoli so obetavne spojine za preprečevanje in potencialno zdravljenje številnih človeških patologij, med katere sodijo tudi nevrodegenerativne bolezni. Potrebno je poudariti, da je študij vpliva naravnih spojin na človeško telo zelo kompleksen, saj je pri tem potrebno upoštevati številne faktorje. Obstajajo namreč bistvene razlike med delovanjem čistih učinkovin in učinkom naravnih izvlečkov, ki vsebujejo mnoge spojine, ki lahko med seboj vplivajo tudi sinergistično. Pomembni pa so 


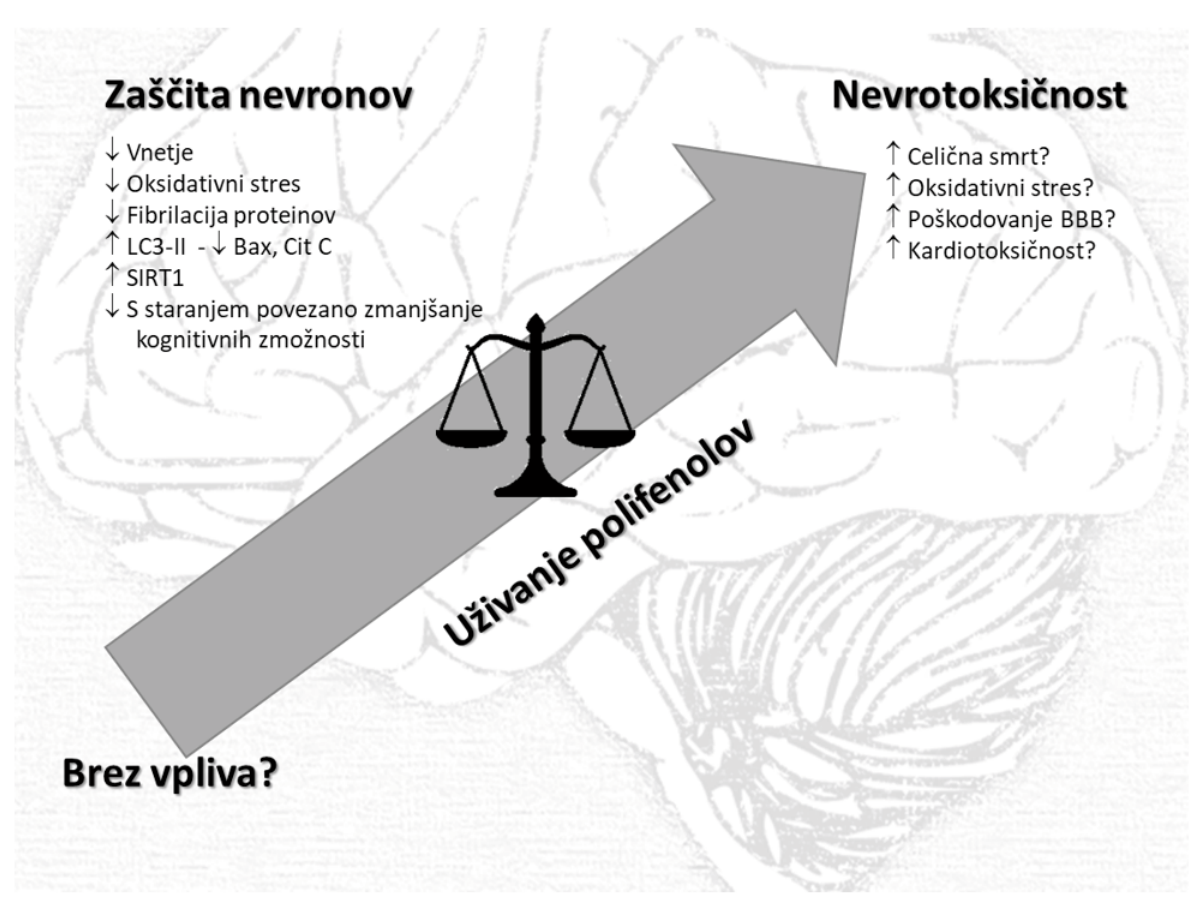

Slika 3: Prikaz glavnih mehanizmov zaščite nevronov s polifenoli z možnimi varnostnimi pomisleki, ki bi bili lahko posledica prevelikih zaužitih količin

Figure 3: Presentation of main polyphenol neuroprotection mechanisms with potential toxic effects caused by overconsumption.

tudi učinki njihovih modificiranih ali razgradnih produktov, ki nastajajo $\mathrm{v}$ procesu prebave in/ali prenosa po telesu. Poleg že omenjenega prehoda preko BBB ne smemo spregledati prehoda spojin iz prebavil v krvni obtok, pomemben pa je tudi njihov vpliv na spolne celice ali zarodek. Zavedati se je tudi potrebno, da vpliv posameznih spojin ni vedno neposreden, saj v nekaterih primerih niso potrebne velike količine učinkovine na tarčnem mestu.

Vse to bo potrebno upoštevati v nadaljnjih raziskavah, ki bodo usmerjene v ugotavljanje morebitnih škodljivih stranskih učinkov, zlasti zaradi njihovega potencialnega kopičenja v organizmu (Slika 3). Potrebnih bo še več študij, da bi ugotovili, kakšna je povezava med količino zaužitih polifenolov in njihovimi varnimi plazemskimi koncentracijami. Dokler ne bodo opravljene te raziskave, je priporočljivo uživanje živil bogatih s polifenoli, kot so npr. sadje, zelenjava, čaj in kava. Prekomerna uporaba prehranskih dopolnil, ki vsebujejo velike količine polifenolov, pa je še vedno slabo regulirana s strani zakonodaje, kar lahko povzroči previsoke vsebnosti teh spojin $\mathrm{v}$ organizmu in večje tveganje za škodljive učinke. Kljub temu so takšna dopolnila lahko koristen vir, kadar je normalno prehranjevanje onemogočeno ob določenih bolezenskih stanjih ali dietah.

\section{VIRI}

Abib, R. T., Peres, K. C., Barbosa, A. M., Peres, T. V., Bernardes, A., Zimmermann, L. M., . . Gottfried, C. (2011). Epigallocatechin-3-gallate protects rat brain mitochondria against cadmium-induced damage. Food and Chemical Toxicology, 49(10), 2618-2623. https://doi:10.1016/j.fct.2011.07.006

Afshari, K., Haddadi, N. S., Haj-Mirzaian, A., Farzaei, M. H., Rohani, M. M., Akramian, F., . . A Abdolghaffari, A. H. (2019). Natural flavonoids for the prevention of colon cancer: A comprehensive review of preclinical and clinical studies. Journal of Cellular Physiology, https://doi:10.1002/ jcp. 28777

Afzal, M., Safer, A. M., \& Menon, M. (2015). Green tea polyphenols and their potential role in health and disease. Inflammopharmacology, 23(4), 151-161. https://doi:10.1007/ s10787-015-0236-1

Amor, S., Puentes, F., Baker, D., \& van, d. V. (2010). Inflammation in neurodegenerative diseases. Immunology, 129(2), 154-169.

Anandhan, A., Essa, M. M., \& Manivasagam, T. (2013). Therapeutic attenuation of neuroinflammation and apoptosis by black tea theaflavin in chronic MPTP/probenecid model of Parkinson's disease. Neurotoxicity Research, 23(2), 166-173. https://doi:10.1007/s12640-012-9332-9

Aquilano, K., Baldelli, S., Rotilio, G., \& Ciriolo, M. R. (2008). Role of nitric oxide synthases in Parkinson's disease: a re- 
view on the antioxidant and anti-inflammatory activity of polyphenols. Neurochemical Research, 33(12), 2416-2426.

Bernas, M. J., Cardoso, F. L., Daley, S. K., Weinand, M. E., Campos, A. R., Ferreira, A. J., . . Brito, M. A. (2010). Establishment of primary cultures of human brain microvascular endothelial cells to provide an in vitro cellular model of the blood-brain barrier. Nature Protocols, 5(7), 1265-1272.

Boyanapalli, S. S., \& Tony Kong, A. N. (2015). "Curcumin, the King of Spices": Epigenetic Regulatory Mechanisms in the Prevention of Cancer, Neurological, and Inflammatory Diseases. Current Pharmacology Reports, 1(2), 129-139. https:// doi:10.1007/s40495-015-0018-x

Bravo, L. (1998). Polyphenols: chemistry, dietary sources, metabolism, and nutritional significance. Nutrition Reviews, 56(11), 317-333. https://doi:10.1111/j.1753-4887.1998. tb01670.x

Calabrese, V., Guagliano, E., Sapienza, M., Panebianco, M., Calafato, S., Puleo, E., ... Stella, A. G. (2007). Redox regulation of cellular stress response in aging and neurodegenerative disorders: role of vitagenes. Neurochemical Research, 32(45), 757-773.

Cao, W., Dou, Y., \& Li, A. (2018). Resveratrol Boosts Cognitive Function by Targeting SIRT1. Neurochemical Research, 43(9), 1705-1713. https://doi:10.1007/s11064-018-2586-8

Capiralla, H., Vingtdeux, V., Zhao, H., Sankowski, R., Al-Abed, Y., Davies, P., \& Marambaud, P. (2012). Resveratrol mitigates lipopolysaccharide- and Abeta-mediated microglial inflammation by inhibiting the TLR4/NF-kappaB/STAT signaling cascade. Journal of Neurochemistry, 120(3), 461472.

Carrasco-Pozo, C., Cires, M. J., \& Gotteland, M. (2019). Quercetin and Epigallocatechin Gallate in the Prevention and Treatment of Obesity: From Molecular to Clinical Studies. Journal of Medicinal Food, https://doi:10.1089/ jmf.2018.0193

Chang, S. C., Cassidy, A., Willett, W. C., Rimm, E. B., O’Reilly, E. J., \& Okereke, O. I. (2016). Dietary flavonoid intake and risk of incident depression in midlife and older women. American Journal of Clinical Nutrition, 104(3), 704-714. https://doi:10.3945/ajcn.115.124545

Charradi, K., Mahmoudi, M., Bedhiafi, T., Jebari, K., El May, M. V., Limam, F., \& Aouani, E. (2018). Safety evaluation, anti-oxidative and anti-inflammatory effects of subchronically dietary supplemented high dosing grape seed powder (GSP) to healthy rat. Biomedicine \& Pharmacotherapy, 107, 534-546. https://doi:10.1016/j.biopha.2018.08.031

Costa, S. L., Silva, V. D., Dos Santos Souza, C., Santos, C. C., Paris, I., Munoz, P., \& Segura-Aguilar, J. (2016). Impact of Plant-Derived Flavonoids on Neurodegenerative Diseases. Neurotoxicity Research, 30(1), 41-52. https://doi:10.1007/ s12640-016-9600-1

Crozier, A., Jaganath, I. B., \& Clifford, M. N. (2009). Dietary phenolics: chemistry, bioavailability and effects on health. Natural Product Reports, 26(8), 1001-1043. https:// doi:10.1039/b802662a

D’Archivio, M., Filesi, C., Di Benedetto, R., Gargiulo, R., Giovannini, C., \& Masella, R. (2007). Polyphenols, dietary sources and bioavailability. Annali dell'Istituto Superiore Sanita, 43(4), 348-361.
D’Archivio, M., Filesi, C., Varì, R., Scazzocchio, B., \& Masella, R. (2010). Bioavailability of the Polyphenols: Status and Controversies. International Journal of Molecular Sciences, 11(4), 1321-1342. https://doi:10.3390/ijms11041321

Dajas, F., Abin-Carriquiry, J. A., Arredondo, F., Blasina, F., Echeverry, C., Martinez, M., . . . Vaamonde, L. (2015). Quercetin in brain diseases: Potential and limits. Neurochemistry International, 89, 140-148. https://doi:10.1016/j. neuint.2015.07.002

Deli, M. A., Ábrahám, C. S., Kataoka, Y., \& Niwa, M. (2005). Permeability Studies on In Vitro Blood-Brain Barrier Models: Physiology, Pathology, and Pharmacology. Cellular and Molecular Neurobiology, 25(1), 59-127. https://doi:10.1007/ s10571-004-1377-8

Egert, S., Wolffram, S., Bosy-Westphal, A., Boesch-Saadatmandi, C., Wagner, A. E., Frank, J., . . Mueller, M. J. (2008). Daily quercetin supplementation dose-dependently increases plasma quercetin concentrations in healthy humans. The Journal of Nutrition, 138(9), 1615-1621. https:// doi:138/9/1615

Faria, A., Mateus, N., \& Calhau, C. (2012). Flavonoid transport across blood-brain barrier: Implication for their direct neuroprotective actions. Nutrition and Aging, 1, 89-97. https:// doi:10.3233/NUA-2012-0005

Faria, A., Meireles, M., Fernandes, I., Santos-Buelga, C., Gonzalez-Manzano, S., Duenas, M., . . Calhau, C. (2014). Flavonoid metabolites transport across a human BBB model. Food Chemistry, 149, 190-196.

Faria, A., Pestana, D., Teixeira, D., Azevedo, J., Freitas, V., Mateus, N., \& Calhau, C. (2010). Flavonoid transport across RBE4 cells: A blood-brain barrier model. Cellular \& Molecular Biology Letters, 15(2), 234-241. https://doi:10.2478/ s11658-010-0006-4

Fernandes, A., Falcao, A. S., Silva, R. F., Gordo, A. C., Gama, M. J., Brito, M. A., \& Brites, D. (2006). Inflammatory signalling pathways involved in astroglial activation by unconjugated bilirubin. Journal of Neurochemistry, 96(6), 1667-1679.

Garcia, G., Nanni, S., Figueira, I., Ivanov, I., McDougall, G. J., Stewart, D., . . Santos, C. N. (2017). Bioaccessible (poly) phenol metabolites from raspberry protect neural cells from oxidative stress and attenuate microglia activation. Food Chemistry, 215, 274-283. https://doi:10.1016/j.foodchem.2016.07.128

Glass, C. K., Saijo, K., Winner, B., Marchetto, M. C., \& Gage, F. H. (2010). Mechanisms underlying inflammation in neurodegeneration. Cell, 140(6), 918-934.

Godos, J., Castellano, S., Ray, S., Grosso, G., \& Galvano, F. (2018). Dietary Polyphenol Intake and Depression: Results from the Mediterranean Healthy Eating, Lifestyle and Aging (MEAL) Study. Molecules, 23(5). https://doi:10.3390/ molecules 23050999

Godos, J., Marventano, S., Mistretta, A., Galvano, F., \& Grosso, G. (2017). Dietary sources of polyphenols in the Mediterranean healthy Eating, Aging and Lifestyle (MEAL) study cohort. International Journal of Food Sciences and Nutrition, 68(6), 750-756. https://doi:10.1080/09637486.2017.128587 0

Granzotto, A., \& Zatta, P. (2014). Resveratrol and Alzheimer's disease: message in a bottle on red wine and cognition. 
Frontiers in Aging Neuroscience, 6, 95. https://doi:10.3389/ fnagi.2014.00095

Gray, N. E., Zweig, J. A., Caruso, M., Zhu, J. Y., Wright, K. M., Quinn, J. F., \& Soumyanath, A. (2018). Centella asiatica attenuates hippocampal mitochondrial dysfunction and improves memory and executive function in beta-amyloid overexpressing mice. Molecular and Cell Neuroscience, 93, 1-9. https://doi:10.1016/j.mcn.2018.09.002

Grosso, G., Stepaniak, U., Topor-Madry, R., Szafraniec, K., \& Pajak, A. (2014). Estimated dietary intake and major food sources of polyphenols in the Polish arm of the HAPIEE study. Nutrition, 30(11-12), 1398-1403. https:// doi:10.1016/j.nut.2014.04.012

Hartman, R. E., Shah, A., Fagan, A. M., Schwetye, K. E., Parsadanian, M., Schulman, R. N., ... Holtzman, D. M. (2006). Pomegranate juice decreases amyloid load and improves behavior in a mouse model of Alzheimer's disease. Neurobiology of Disease, 24(3), 506-515.

Hu, J., Webster, D., Cao, J., \& Shao, A. (2018). The safety of green tea and green tea extract consumption in adults - Results of a systematic review. Regulatory Toxicology and Pharmacology, 95, 412-433. https://doi:10.1016/j.yrtph.2018.03.019

Hur, S. J., Lim, B. O., Decker, E. A., \& McClements, D. J. (2011). In vitro human digestion models for food applications. Food Chemistry, 125(1), 1-12. https://doi:10.1016/j.foodchem.2010.08.036

Johnson, W. D., Morrissey, R. L., Usborne, A. L., Kapetanovic, I., Crowell, J. A., Muzzio, M., \& McCormick, D. L. (2011). Subchronic oral toxicity and cardiovascular safety pharmacology studies of resveratrol, a naturally occurring polyphenol with cancer preventive activity. Food and Chemical Toxicology, 49(12), 3319-3327. https://doi:10.1016/j. fct.2011.08.023

Kay, C. D., Mazza, G. J., \& Holub, B. J. (2005). Anthocyanins exist in the circulation primarily as metabolites in adult men. The Journal of Nutrition, 135(11), 2582-2588. https:// doi:135/11/2582 [pii]

Kelly, E., Vyas, P., \& Weber, J. T. (2017). Biochemical Properties and Neuroprotective Effects of Compounds in Various Species of Berries. Molecules, 23(1). https://doi:10.3390/ molecules 23010026

Lee, H. H., Yang, L. L., Wang, C. C., Hu, S. Y., Chang, S. F., \& Lee, Y. H. (2003). Differential effects of natural polyphenols on neuronal survival in primary cultured central neurons against glutamate- and glucose deprivation-induced neuronal death. Brain Research, 986(1-2), 103-113.

Lee, J. H., Moon, J. H., Kim, S. W., Jeong, J. K., Nazim, U. M., Lee, Y. J., . . . Park, S. Y. (2015). EGCG-mediated autophagy flux has a neuroprotection effect via a class III histone deacetylase in primary neuron cells. Oncotarget, 6(12), 97019717. https://doi:10.18632/oncotarget.3832

Liu, D., Perkins, J. T., \& Hennig, B. (2016). EGCG prevents PCB-126-induced endothelial cell inflammation via epigenetic modifications of NF-kappaB target genes in human endothelial cells. The Journal of Nutritional Biochemistry, 28, 164-170. https://doi:10.1016/j.jnutbio.2015.10.003

Liu, Z., Liu, D., Cheng, J., Mei, S., Fu, Y., Lai, W., . . Lynch, B. S. (2017). Lipid-soluble green tea extract: Genotoxicity and subchronic toxicity studies. Regulatory Toxicology and Pharmacology, 86, 366-373. https://doi:10.1016/j.yrtph.2017.04.004

Lorenzo, J. M., Mousavi Khaneghah, A., Gavahian, M., Marszalek, K., Es, I., Munekata, P. E. S., . . . Barba, F. J. (2019). Understanding the potential benefits of thyme and its derived products for food industry and consumer health: From extraction of value-added compounds to the evaluation of bioaccessibility, bioavailability, anti-inflammatory, and antimicrobial activities. Critical Reviews in Food Science and Nutrition, 59(18), 2879-2895. https://doi:10.1080 /10408398.2018.1477730

Manach, C., Scalbert, A., Morand, C., Remesy, C., \& Jimenez, L. (2004). Polyphenols: food sources and bioavailability. The American Journal of Clinical Nutrition, 79(5), 727-747.

Mandel, S., Amit, T., Reznichenko, L., Weinreb, O., \& Youdim, M. B. (2006). Green tea catechins as brain-permeable, natural iron chelators-antioxidants for the treatment of neurodegenerative disorders. Molecular Nutrition \& Food Research, 50(2), 229-234.

Mani, S., Sekar, S., Barathidasan, R., Manivasagam, T., Thenmozhi, A. J., Sevanan, M., . . S Sakharkar, M. K. (2018). Naringenin Decreases alpha-Synuclein Expression and Neuroinflammation in MPTP-Induced Parkinson's Disease Model in Mice. Neurotoxicity Research, 33(3), 656-670. https://doi:10.1007/s12640-018-9869-3

Marranzano, M., Rosa, R. L., Malaguarnera, M., Palmeri, R., Tessitori, M., \& Barbera, A. C. (2018). Polyphenols: Plant Sources and Food Industry Applications. Current Pharmaceutical Design, 24(35), 4125-4130. https://doi:10.2174/138 1612824666181106091303

Menard, C., Bastianetto, S., \& Quirion, R. (2013). Neuroprotective effects of resveratrol and epigallocatechin gallate polyphenols are mediated by the activation of protein kinase $\mathrm{C}$ gamma. Frontiers in Cellular Neuroscience, 7, 281. https:// doi:10.3389/fncel.2013.00281

Mereles, D., \& Hunstein, W. (2011). Epigallocatechin-3-gallate (EGCG) for Clinical Trials: More Pitfalls than Promises? International Journal of Molecular Sciences, 12(12), 55925603. https://doi:10.3390/ijms12095592

Minekus, M., Alminger, M., Alvito, P., Ballance, S., Bohn, T., Bourlieu, C., . . Brodkorb, A. (2014). A standardised static in vitro digestion method suitable for food - an international consensus. Food \& Function, 5(6), 1113-1124. https:// doi: $10.1039 / \mathrm{c} 3$ fo6 $60702 \mathrm{j}$

Molino, S., Dossena, M., Buonocore, D., Ferrari, F., Venturini, L., Ricevuti, G., \& Verri, M. (2016). Polyphenols in dementia: From molecular basis to clinical trials. Life Sciences, 161, 69-77. https://doi:10.1016/j.lfs.2016.07.021

Mythri, R. B., \& Bharath, M. M. (2012). Curcumin: a potential neuroprotective agent in Parkinson's disease. Current Pharmaceutical Design, 18(1), 91-99.

Noble, W., \& Burns, M. P. (2010). Challenges in neurodegeneration research. Frontiers in Psych., 1(7), 1-2.

Noda, Y., Kaneyuki, T., Mori, A., \& Packer, L. (2002). Antioxidant activities of pomegranate fruit extract and its anthocyanidins: delphinidin, cyanidin, and pelargonidin. Journal of Agricultural and Food Chemistry, 50(1), 166-171.

Nones, J., Stipursky, J., Costa, S. L., \& Gomes, F. C. (2010). Flavonoids and astrocytes crosstalking: implications for 
brain development and pathology. Neurochemical Research, 35(7), 955-966. https://doi:10.1007/s11064-010-0144-0

Oliveira, M. R., Nabavi, S. F., Daglia, M., Rastrelli, L., \& Nabavi, S. M. (2016). Epigallocatechin gallate and mitochondria-A story of life and death. Pharmacological Research, 104, 7085. https://doi:10.1016/j.phrs.2015.12.027

Ono, K., Yoshiike, Y., Takashima, A., Hasegawa, K., Naiki, H., \& Yamada, M. (2003). Potent anti-amyloidogenic and fibrildestabilizing effects of polyphenols in vitro: implications for the prevention and therapeutics of Alzheimer's disease. Journal of Neurochemistry, 87(1), 172-181.

Palazzi, L., Bruzzone, E., Bisello, G., Leri, M., Stefani, M., Bucciantini, M., \& Polverino de Laureto, P. (2018). Oleuropein aglycone stabilizes the monomeric alpha-synuclein and favours the growth of non-toxic aggregates. Scientific Reports, 8(1), 8337. https://doi:10.1038/s41598-018-26645-5

Pan, P. T., Lin, H. Y., Chuang, C. W., Wang, P. K., Wan, H. C., Lee, M. C., \& Kao, M. C. (2019). Resveratrol alleviates nuclear factor-kappaB-mediated neuroinflammation in vasculitic peripheral neuropathy induced by ischemiareperfusion via suppressing endoplasmic reticulum stress. Clinical Experimental Pharmacology and Physiology, https://doi:10.1111/1440-1681.13105

Pandareesh, M. D., Mythri, R. B., \& Srinivas Bharath, M. M. (2015). Bioavailability of dietary polyphenols: Factors contributing to their clinical application in CNS diseases. Neurochemistry International, 89, 198-208. https:// doi:10.1016/j.neuint.2015.07.003

Parikh, A., Kathawala, K., Li, J., Chen, C., Shan, Z., Cao, X., . . . Garg, S. (2018). Curcumin-loaded self-nanomicellizing solid dispersion system: part II: in vivo safety and efficacy assessment against behavior deficit in Alzheimer disease. Drug Delivery and Translational Research, 8(5), 1406-1420. https://doi:10.1007/s13346-018-0570-0

Perez-Jimenez, J., Neveu, V., Vos, F., \& Scalbert, A. (2010). Identification of the 100 richest dietary sources of polyphenols: an application of the Phenol-Explorer database. European Journal of Clinical Nutrition, 64 Suppl 3, S112-120. https:// doi:10.1038/ejcn.2010.221

Pogačnik, L., Pirc, K., Palmela, I., Skrt, M., Kim, K. S., Brites, D., ... Silva, R. F. (2016). Potential for brain accessibility and analysis of stability of selected flavonoids in relation to neuroprotection in vitro. Brain Research, 1651, 17-26. https:// doi:10.1016/j.brainres.2016.09.020

Poti, F., Santi, D., Spaggiari, G., Zimetti, F., \& Zanotti, I. (2019). Polyphenol Health Effects on Cardiovascular and Neurodegenerative Disorders: A Review and Meta-Analysis. International Journal of Molecular Sciences, 20(2). https:// doi:10.3390/ijms20020351

Rasheed, N. O. A., Ahmed, L. A., Abdallah, D. M., \& El-Sayeh, B. M. (2018). Paradoxical cardiotoxicity of intraperitoneally-injected epigallocatechin gallate preparation in diabetic mice. Scientific Reports, 8(1), 7880. https:/doi:10.1038/ s41598-018-25901-y

Rezai-Zadeh, K., Arendash, G. W., Hou, H., Fernandez, F., Jensen, M., Runfeldt, M., . . Tan, J. (2008). Green tea epigallocatechin-3-gallate (EGCG) reduces beta-amyloid mediated cognitive impairment and modulates tau pathology in
Alzheimer transgenic mice. Brain Reserch, 1214, 177-187. https://doi:10.1016/j.brainres.2008.02.107

Sangeetha, M. K., Vallabi, D. E., Sali, V. K., Thanka, J., \& Vasanthi, H. R. (2013). Sub-acute toxicity profile of a modified resveratrol supplement. Food and Chemical Toxicology, 59, 492-500. https://doi:10.1016/j.fct.2013.06.037

Schimidt, H. L., Garcia, A., Martins, A., Mello-Carpes, P. B., \& Carpes, F. P. (2017). Green tea supplementation produces better neuroprotective effects than red and black tea in Alzheimer-like rat model. Food Research International, $100(\mathrm{Pt}$ 1), 442-448. https://doi:10.1016/j.foodres.2017.07.026

Schraufstatter, E., \& Bernt, H. (1949). Antibacterial action of curcumin and related compounds. Nature, 164(4167), 456.

Shen, C. L., Brackee, G., Song, X., Tomison, M. D., Finckbone, V., Mitchell, K. T., . . Wang, J. S. (2017). Safety Evaluation of Green Tea Polyphenols Consumption in Middle-aged Ovariectomized Rat Model. Journal of Food Science, 82(9), 2192-2205. https://doi:10.1111/1750-3841.13745

Solanki, I., Parihar, P., Mansuri, M. L., \& Parihar, M. S. (2015). Flavonoid-Based Therapies in the Early Management of Neurodegenerative Diseases. Advances in Nutrition, 6(1), 64-72. https://doi:10.3945/an.114.007500

Sun, A. Y., Simonyi, A., \& Sun, G. Y. (2002). The "French Paradox" and beyond: neuroprotective effects of polyphenols. Free Radical Biology \& Medicine, 32(4), 314-318.

Szwajgier, D., Borowiec, K., \& Pustelniak, K. (2017). The Neuroprotective Effects of Phenolic Acids: Molecular Mechanism of Action. Nutrients, 9(5). https://doi:10.3390/nu9050477

Tarawneh, R., \& Galvin, J. E. (2010). Potential future neuroprotective therapies for neurodegenerative disorders and stroke. Clinics in Geriatric Medicine, 26(1), 125-147.

Tili, E., \& Michaille, J. J. (2016). Promiscuous Effects of Some Phenolic Natural Products on Inflammation at Least in Part Arise from Their Ability to Modulate the Expression of Global Regulators, Namely microRNAs. Molecules, 21(9). https://doi:10.3390/molecules21091263

Tresserra-Rimbau, A., Lamuela-Raventos, R. M., \& Moreno, J. J. (2018). Polyphenols, food and pharma. Current knowledge and directions for future research. Biochemical Pharmacology, 156, 186-195. https://doi:10.1016/j.bcp.2018.07.050

Tresserra-Rimbau, A., Medina-Remon, A., Perez-Jimenez, J., Martinez-Gonzalez, M. A., Covas, M. I., Corella, D., . . . Lamuela-Raventos, R. M. (2013). Dietary intake and major food sources of polyphenols in a Spanish population at high cardiovascular risk: the PREDIMED study. Nutrition, Metabolism \& Cardiovascular Diseases, 23(10), 953-959. https://doi:10.1016/j.numecd.2012.10.008

Ullah, H., \& Khan, H. (2018). Anti-Parkinson Potential of Silymarin: Mechanistic Insight and Therapeutic Standing. Frontiers in Pharmacology, 9. https://doi:10.3389/ fphar.2018.00422

Ulusoy, H. G., \& Sanlier, N. (2019). A minireview of quercetin: from its metabolism to possible mechanisms of its biological activities. Critical Reviews in Food Science and Nutrition, 1-14. https://doi:10.1080/10408398.2019.1683810

Virmani, A., Pinto, L., Binienda, Z., \& Ali, S. (2013). Food, nutrigenomics, and neurodegeneration--neuroprotection 
by what you eat! Molecular Neurobiology, 48(2), 353-362. https://doi:10.1007/s12035-013-8498-3

Vlachojannis, C., Zimmermann, B. F., \& Chrubasik-Hausmann, S. (2015). Efficacy and safety of pomegranate medicinal products for cancer. Evidence-Based Complementary Alternative Medicine, 2015, 258598. https:// doi:10.1155/2015/258598

Wang, D., Meng, J., Xu, K., Xiao, R., Xu, M., Liu, Y., . . . Liu, L. (2012). Evaluation of oral subchronic toxicity of Puerh green tea (camellia sinensis var. assamica) extract in Sprague Dawley rats. Journal of Ethnopharmacology, 142(3), 836-844. https://doi:10.1016/j.jep.2012.06.011

Weinreb, O., Mandel, S., Amit, T., \& Youdim, M. B. (2004). Neurological mechanisms of green tea polyphenols in Alzheimer's and Parkinson's diseases. The Journal of Nutritional Biochemistry, 15(9), 506-516.

West, T., Atzeva, M., \& Holtzman, D. M. (2007). Pomegranate polyphenols and resveratrol protect the neonatal brain against hypoxic-ischemic injury. Developmental Neuroscience, 29(4-5), 363-372.

Willis, L. M., Freeman, L., Bickford, P. C., Quintero, E. M., Umphlet, C. D., Moore, A. B., . . Granholm, A. C. (2010). Blueberry supplementation attenuates microglial activation in hippocampal intraocular grafts to aged hosts. Glia, 58(6), 679-690.

Yamamoto, N., Shibata, M., Ishikuro, R., Tanida, M., Taniguchi, Y., Ikeda-Matsuo, Y., \& Sobue, K. (2017). Epigallocatechin gallate induces extracellular degradation of amyloid beta-protein by increasing neprilysin secretion from astrocytes through activation of ERK and PI3K pathways. Neuroscience, 362, 70-78. https://doi:10.1016/j.neuroscience.2017.08.030

Yu, S., Wang, X., He, X., Wang, Y., Gao, S., Ren, L., \& Shi, Y.
(2016). Curcumin exerts anti-inflammatory and antioxidative properties in 1-methyl-4-phenylpyridinium ion $(\mathrm{MPP}(+))$-stimulated mesencephalic astrocytes by interference with TLR4 and downstream signaling pathway. Cell Stress Chaperones, 21(4), 697-705. https://doi:10.1007/ s12192-016-0695-3

Zafra-Stone, S., Yasmin, T., Bagchi, M., Chatterjee, A., Vinson, J. A., \& Bagchi, D. (2007). Berry anthocyanins as novel antioxidants in human health and disease prevention. Molecular Nutrition \& Food Research, 51(6), 675-683.

Zamora-Ros, R., Knaze, V., Rothwell, J. A., Hemon, B., Moskal, A., Overvad, K., . . S Scalbert, A. (2016). Dietary polyphenol intake in Europe: the European Prospective Investigation into Cancer and Nutrition (EPIC) study. European Journal of Nutrition, 55(4), 1359-1375. https://doi:10.1007/s00394015-0950-x

Zhang, F., Wang, H., Wu, Q., Lu, Y., Nie, J., Xie, X., \& Shi, J. (2013). Resveratrol protects cortical neurons against microglia-mediated neuroinflammation. Phytotherapy Research, 27(3), 344-349. https://doi:10.1002/ptr.4734

Zhang, T., Zhang, J., Derreumaux, P., \& Mu, Y. (2013). Molecular mechanism of the inhibition of EGCG on the Alzheimer Abeta(1-42) dimer. The Journal of Physical Chemistry B, 117(15), 3993-4002. https://doi:10.1021/jp312573y

Zhang, X., Wu, M., Lu, F., Luo, N., He, Z. P., \& Yang, H. (2014). Involvement of alpha7 $\mathrm{nAChR}$ signaling cascade in epigallocatechin gallate suppression of beta-amyloid-induced apoptotic cortical neuronal insults. Molecular Neurobiology, 49(1), 66-77. https://doi:10.1007/s12035-013-8491-x

Zhu, M., Han, S., \& Fink, A. L. (2013). Oxidized quercetin inhibits alpha-synuclein fibrillization. Biochimica et Biophysica Acta, 1830(4), 2872-2881. https://doi:10.1016/j. bbagen.2012.12.027 